\title{
Treatment of Infertility by Natural Factors in a Patient Who Had Seven Failed Procedures of In Vitro Fertilization
}

\author{
Goranka Radmilović ${ }^{1}$, Valentina Matijević ${ }^{2 *}$, Alenka Višnić ${ }^{3}$, Zlatica Vezmar ${ }^{4}$ \\ ${ }^{1}$ Special Hospital for Medical Rehabilitation, Daruvarske toplice, Julijev park 1, 43500 Daruvar, Croatia, \\ Faculty of Medicine, Cara Hadrijana 10e, 31000 Osijek, Croatia \\ ${ }^{2}$ University Department of Rheumatology, Physical Medicine and Rehabilitation, Sestre Milosrdnice University \\ Hospital Center, Vinogradska cesta 29, 10000 Zagreb, Croatia, Faculty of Medicine, Cara Hadrijana 10e, \\ 31000 Osijek, Croatia \\ ${ }^{3}$ General Hospital Pakrac, Bolnička ulica 68, 34550 Pakrac, Croatia \\ ${ }^{4}$ Special Hospital for Medical Rehabilitation, Daruvarske toplice, Julijev park 1, 43500 Daruvar, Croatia
}

*Corresponding Author: Valentina Matijević, University Department of Rheumatology, Physical Medicine and Rehabilitation, Sestre Milosrdnice University Hosptal Center, Vinogradska cesta 29, 10000 Zagreb, Croatia, Faculty of Medicine, Cara Hadrijana 10e, 31000 Osijek, Croatia. Email: valentina.matijevic@gmail.com

\begin{abstract}
Infertility is not rare today, it affects about 15\% of couples around the world. It is usually treated by in vitro fertilization, method of assisted fertilization, which allows many couples to create offspring. On the other hand, this infertility tretment is still unsuccessful in many cases and unavailable to everyone. We report a case of a 33-year old woman who had seven unsuccessful atempts of conception by in vitro fertilization and neither of those didn't result with embrio implantation. In Special Hospital for Medical Rehabilitation, Daruvarske toplice, infertility treatment has been conducted by natural facors during 3 weeks. The treatment included fangotherapy, bathing in thermo-mineral water, hand massage nad hydro massage. Two months after the end of the therapy she got pregnant by natural way and gave birth to twins, boy and girl. With these case report we wanted to point out that the natural factor is one of the chioces for infertile patients who, for some reason, do not want methods of assisted fertilization or the method was unsuccessful but also a positive introduction to the medical assisted fertilization.
\end{abstract}

Keywords: Infertility treatment, In vitro fertilization, Thermo-mineral water, Fangotherapy, Natural factors

\section{INTRODUCTION}

According to the UN Declaration on Fundamental Human Rights, the privilege of creating marriage, familiy and offspring is one of the foundational human rights. ${ }^{[1]}$ Because of the infertility, that affecting $15 \%$ of couples around the world (around 48.5 millions of couples), all marriaged couples do not have offspring. In about fifty percent of cases the cause of couples infertility is female infertility while the rest is related to the infertility of men, both partners or is idiopathic where the cause of infertility is unexplained. Infertility is defined as lack of desired pregnancy with regular and without contraceptive intercourses within a period of at least one year. ${ }^{[2]}$

Infertility is treated by methods of assisted fertilization and the mostly used method is conventional in vitro fertilizationi in stimulated cycle, which is expensive and aggresive treatment, often unpleasant for patient with lot of potentional compications. ${ }^{[3]}$ Less aggressive treatment of infertility is in vitro fertilisation in natural cycle or in cycle with mild stimulation . ${ }^{[3]}$ The treatment in natural cycle is less successful than expected and for greater performance drugs are used to stimulate ovulation, most commonly exogenous gonadotropins. ${ }^{[4]}$

In Special Hospital fod Medical Rehabilitation, Daruvarske toplice, the problem of infertility is treated by natural factors which are now, at the time of 21th century medicine, coming to another plan. We have witnessed a lot of studies conducted on the subject of infertility treatment as well as on the beneficial effects of natural factors generally but on the other hand just a few that mention a natural factor in infertility treatment. The natural factor is one of the 
chioces for infertile patients who do not want methods of assisted fertilization because of the ethical or religious reasons or the mentioned method was unsuccessful, but it is also a positive introduction to the medical assisted fertilization. In this hospital the treatment of infertility takes place through the program called the 'Joy of Life' which contains bathing in the tub filled with thermo-mineral water, application of mineral mud called fango on the lumbo-sacral spine and ond the area over the oviducts and ovaries, hydro massage of the lower back and belly in the thermal water as well as hand massage and medical gymnastic for plevic muscles. Bowen and Emmett techniques are also carried out if is necessary. The first, Bowen technique, is a therapy that uses a light, non-invasive pressure applied to specific and prescribed locations throughout the body to trigger the body's own self-healing powers. ${ }^{[5]}$ The Emmett technique is a remedial therapy that works in harmony with sensory and muscular receptors and implies light weight fingerprinting at certain trigger points which are called 'Emmett Points'. ${ }^{[6]}$

The treatment duration is not predetermined and is individual, usually takes two to three weeks between two periods. Husband's visit is recommended at the predicted time of ovulation. If necessary, therapy repeats after six months. Hospital therapy can be performed stationary or ambulantly.

All treatments are prescribed by specialist physicians and conducted by professional physiotherapists.

\section{Materials and Methods - Case REPORT}

A 33-year old woman, married for ten years, had seven unsuccessful atempts of conception by assisted ferrtilization called stimulated in vitro fertilization, neither of those didn't result with embrio implantation. She comes to Special Hospital for Medical Rehabilitation, Daruvarske toplice, to treat infertiliy naturally. Her's and her husband's medical findings are completely normal and the cause of infertility and failures of assisted fertilization remained unclear. She has a very painful menstrual periods.

The woman has performed ambulatory rehabilitation,through the program called the 'Joy of Life', for 3 weeks. The program included:

a) Bathing in the tub with thermo-mineral water every day for one hour. Thermal water of wild origin, belongs to indifferent hyperthermic $\left(47.5 \quad{ }^{\circ} \mathrm{C}\right)$ water with mineralization below $1 \mathrm{~g} / \mathrm{L}$. According to the international classification, it is calciumhydro-carbonate water. The radioactivity of water is low and ranges from 0.739 to 5.081 Mache's units and its falls with the heat of the source. ${ }^{[7]}$ The chemical composition of the source is almost identical but the temperature is different. The water temperature in tubs is $32-36^{\circ} \mathrm{C}$.

b) Fangotherapy on the lumbo-sacral spine and belly three times per week for 20-30 minutes and mud blend thickness 3-4 centimeters. Fango, mineral mud, was created by millennium deposition of sand, clay and the processes of organic and inorganic decomposition under the influence of thermal water and atmospheric influences with great changes of soil temperature. It consists of azure blue clay mixed with tiny granules of quartz sand, ashes of volcanic origin and other inorganic and organic ingredients. ${ }^{[8]}$ Mineral mud actually came out of the land by digging a dry sediment which is mixed with thermal water and heated to $40^{\circ} \mathrm{C}$. The mud is applied in the form of compress to the affected part of the body and directly to the body. The mudlined part of the body is covered with a cloth, then a rubberized cloth and finally blanket.

c) hand massage of lumbar spine and belly three times a week for 20-30 minutes,

d) hydro massage of the whole body, in thermo-mineral water, every day for 30 minutes.

\section{RESULTS AND DISCUSSION}

One month after the end of the therapy the menstrual period was no longer painful and after 2 months she got pregnant by natural way. The pregnancy was without complications and gave birth to full term and healthy twins, boy and girl.

The availability of in vitro fertilization and a high quality program of it can make a significant contribution to natality and by using these procedures up to $5 \%$ of infants are born per year. ${ }^{[9]}$ With this case report we present some other way to treat infertility, natural factor.

Not only because of the long-lasting positive experience in the treatment of infertility in Hospital for Medical Rehabilitation,Daruvarske toplice, but also because of the known effects that natural factors have on the body system.

Bathing in tubs with thermo-mineral water have positive physical and chemical effect. Physical action of baths in thermal water has a thermal 
effect, while chemical activity implies ion minerals that cause hyperemia, reduce inflammation and pain and improve the function of reproductive organs. ${ }^{[10]}$ Fango also has a dual effect. The thermal effect is as in the bath and a chemical effect is in the resorption of cumic acid that acts on the pituitary, and indirectly positive to the other glands with internal excretion. ${ }^{[10,11]}$ In chronic inflammatory centres, the fango acts analgesic, anti-inflammatory and anti-oedematous.

All that has been said so far, explains why natural factors act positively in the treatment of infertility, chronic pain and chronic inflammatory diseases.

Contraindications for baths and fango are acute inflammatory diseases, malignant forms, tuberculosis, severe heart diseases, unregulated hypertension, varicose veins, bleeding disorders, hyperthyroidism, body fatigue and skin diseases other than psoriasis.

\section{CONCLUSION}

The problem of infertility can be very stressful for couples who want to become parents and are prepared for it in every sense. With the advancement of medicine we are witnessing numerous methods of assisted fertilization which are in many cases still unsuccessful and unavailable to everyone. The purpose of this case report is to point out the positive effects of natural factors, first as a therapy for infertility treatment for couples who do not want or are unavailable to any method of assisted fertilization or the method is unsuccessful and second, as a desirable introduction to assisted fertilization methods in pairs who decide on it. In the future is necessary, in order to avoid putting a natural factor in the background, to present more case reports and researches on this field.

\section{REFERENCES}

[1] Lauterpacht, H., The Universal Declaration of Human Rights'. BYIL, 25, 354-370(1948).

[2] Bauman R., Diagnostics and treatment of infertility. Medicina Fluminensis. 45(4), 300312 (2009).
[3] Radaković, B.,NEW STRATEGIES AND RECOMMENDATION EUROPEAN COMMUNITY IN TREATMENT OF INFERTILITY WITH ASSISTED REPRODUCTIVE TECHNOLOGIES. Gynaecologia et Perinatologia, 18(2), 55-60 (2009).

[4] Macklon, N. S., Stouffer, R. L., Giudice, L. C., \& Fauser, B. C., The science behind 25 years of ovarian stimulation for in vitro fertilization. Endocrine reviews, 27(2), 170-207(2006).

[5] Carter, B., Clients' experiences of frozen shoulder and its treatment with Bowen technique. Complementary Therapies in Nursi$n g$ and Midwifery. 8(4), 204-210(2002).

[6] Sharp, V., A comparative study between self myofascial release and Emmett technique effectiveness in the management of fascial (iliotibial band) tightness. (2012). (Online) avaliable at http://emmett-uk.therapistlinkhosting. co.uk (Accessed on 10/09/17).

[7] Pernar, I., Zdravstveni turizam na primjeru Daruvarskih toplica (Doctoral dissertation, University of Zadar. Department of Tourism and Communication Sciences.),(2016).

[8] Mihelčić, G., Kniewald, G., Ivanišević, G., Čepelak, R., Mihelčić, V., \& Vdović, N., Physico-chemical characteristics of the peloid mud from Morinje Bay (eastern Adriatic coast, Croatia): suitability for use in balneo therapy. Environmental geochemistry and health, 34(2), 191-198(2012).

[9] Šimunić V. i sur., Reprodukcijska endokrinologija i neplodnost. Medicinski potpomognuta oplodnja i IVF. Zagreb:Školska knjiga. 471(2012).

[10] I.Jajić i suradnici, Fizikalna Medicina i Opća Rehabilitacija, 2nd ed. Zagreb, Cro Medicinska Naklada, 2000, ch. 29, pp. 296-300.

[11] Giusti, P., Cima, L., Tinello, A., Cozzi, F., Targa, L., Lazzarin, P., \& Todesco, S., Stress hormones liberated by fangotherapy. ACTH and beta-endorphin levels under heat stress. Fortschritte der Medizin. 108(32), 601603(1990).

Citation: Goranka Radmilović, Valentina Matijević, Alenka Višnić, Zlatica Vezmar, Treatment of Infertility by Natural Factors in A Patient Who Had Seven Failed Procedures of In Vitro Fertilization. ARC Journal of Gynecology and Obstetrics. 2017; 2(2):1-3. doi:dx.doi.org/10.20431/2456-0561.0202001.

Copyright: () 2017 Authors. This is an open-access article distributed under the terms of the Creative Commons Attribution License, which permits unrestricted use, distribution, and reproduction in any medium, provided the original author and source are credited. 